\title{
Role of Care for the Prevention of Falls and Fractures among Elderly Persons Living in Long-Term Care Facilities
}

\section{Tatsuya Koike ${ }^{1,2^{*}}$}

${ }^{1}$ Center for Senile Degenerative Disorders (CSDD), Osaka City University Medical School, Osaka, Japan

${ }^{2}$ Search Institute for Bone and Arthritis Disease (SINBAD), Shirahama Foundation for Health and Welfare, Wakayama, Japan

"Corresponding author: Tatsuya Koike, Center for Senile Degenerative Disorders (CSDD), Osaka City University Medical School, Abenoku Asahimachi 1-4-3, Osaka 545-8585, Japan, Tel: Tel: +81-6-6646-6010; Fax: +81-6-6646-6010; E-mail: tatsuya@med.osaka-cu.ac.jp

Received date: Dec 12, 2014, Accepted date: Apr 09, 2015, Published date: Apr 17, 2015

Copyright: (c) 2015 Koike T. This is an open-access article distributed under the terms of the Creative Commons Attribution License, which permits unrestricted use, distribution, and reproduction in any medium, provided the original author and source are credited.

\begin{abstract}
Osteoporosis is the most important disease, along with cognitive disorders, in the aging society, especially in developed countries. Residents of long-term care facilities are a high-risk population for falls and fractures because of their frailty and cognitive disorders. People with internal or external risk factors might fall more frequently. Internal risk factors are endogenous features of each individual, most of which cannot be altered by intervention. On the other hand, external risk factors are environmental conditions, which can be easily modified in many cases. After a fall, the individual suffers an impact force. To reduce this impact force is an alternative measure to prevent fractures, not falls. As an internal risk factor for fracture, bone mineral density (BMD) might become a target for treatment. For that purpose, we have several effective medicines to increase BMD and reduce fracture rates. The most important thing is that caregivers in long-term care facilities develop a better understanding of risk factors for falls and fractures to reduce fall-related injuries of residents.
\end{abstract}

\section{Introduction}

Osteoporosis is the most important disease, along with cognitive disorders, in the aging society, especially in developed countries. The worst scenario of the course of osteoporosis is fracture, disability, and death. Residents of long-term care facilities are a high-risk population for falls and fractures because of their frailty and cognitive disorders [1]. Approximately $5 \%$ of falls result in a fracture [2]. Thus, falls and fall-related injuries are a major health problem for the older population, especially in long-term care facilities. There are many risk factors identified by previous studies for falls and fractures among elderly persons (Figure 1) [3-5]. People have two kinds of risk factors for falls, internal and external risk factors.

Internal risk factors (Figure 1A) are endogenous features of each individual, most of which, such as sex, cannot be altered by interventions. External risk factors (Figure 1B) are environmental conditions that are easily reduced in many cases. Elderly persons with such internal or external risk factors might fall more frequently compared to ones without risk factors. The three most frequent opportunities for falls have been reported to be tripping, slipping, and being unaware of a step (Figure 1C). However, a recent observational study showed that the most frequent cause of falling in long-term care facilities was incorrect weight shifting, not tripping [6]. Using a video capture system to detect real-life falls among residents living in two long-term care facilities in Canada, 227 falls of 130 individuals were captured. The investigators then analyzed the video images of these falls. This finding suggests that a barrier-free strategy might be powerless in preventing such falls in barrier-free facilities.

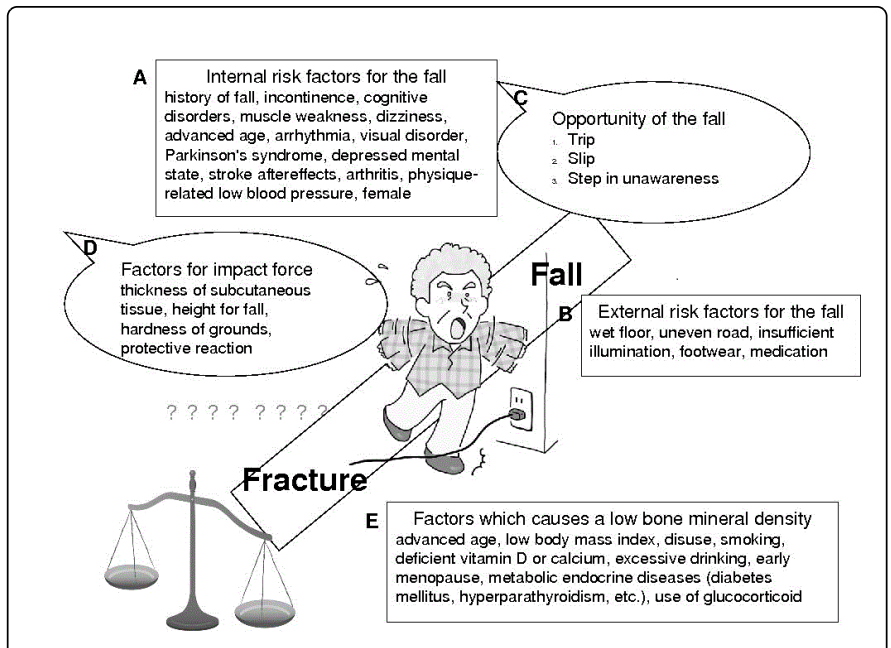

Figure 1: Risk factors for fall and fracture among the elderly, A: Internal risk factors for falls, B: External risk factors for falls, C: Opportunities for falls, D: Factors for impact force, E: Factors that cause a low bone mineral density

Fallers suffer an impact force to their body (Figure 1D). The impact force on bone is determined by the thickness of subcutaneous tissue, height of the fall, hardness of the ground or floor, and the protective reaction. Although younger fallers usually support their body by pushing their hands to the ground, older fallers with poor reflexes receive direct hits to their bodies without a protective reaction. The worst fractures associated with osteoporosis are hip fractures, and a potentially cost-effective method of preventing hip fractures involves the use of hip protectors to reduce the impact force on the hip [7-9]. 
There is a risk factor for fractures related to bone itself. The strength of bones to withstand the shock of a fall depends mainly on bone mineral density (BMD) [10]. BMD isinfluenced by many factors. Factors that induce a low BMD are shown in Figure 1E [11]. These factors include various diseases and prescription drugs. High-energy impact to bone with low BMD causes fractures based on the principle of balance.

If we could change such risk factors, the incidence of serious injuries related to falls might decrease. What do we know? What can we do? The most important point is that caregivers in long-term care facilities may not be necessarily familiar with risk factors for fall and fracture. In this mini review, the author will describe the results and the limitation of previous reliable researches and show future measures for caregivers to prevent fall and fracture in long-term care facilities.

\section{Internal risk factors for falls and fractures (Figure 1A)}

A history of falls is the major independent predictor of future fall risk, but it might be a result of several risk factors [1]. However, caregivers should ask residents about past falls to identify a population at risk [11]. It is well known that hip fractures occur in people with physical inactivity or without obesity. Armstrong and colleagues followed 925,345 postmenopausal women for 6.2 years and found 2,582 hip fractures that required hospitalization [12]. They reported that the relative risk for hip fracture was significantly greater in lean women than in obese subjects. However, for women in any categories of body mass index (BMI), those performing physical exercise had a lower risk for hip fractures than TV-watching women. The authors could not find any interaction between BMI and physical activity for the risk of hip fractures. This research was an observational study, and it is unclear whether physical intervention has some sort of effect on the prevention of hip fracture. However, if residents of a facility are thin, exercises might be recommended. In the future we need to clarify the type of exercise, only walking or more aggressive exercises, to reduce fall and fracture for frail residents.

Among the internal risk factors listed in Figure 1A, only muscle weakness might be improved by exercises. However, in a randomized, controlled trial to evaluate the effectiveness of a multifactorial intervention that had been recommended by an international guideline [13], the intervention did not reduce the fall rate over one year compared to usual care in subjects $\geq 65$ years old with a high risk of recurrent falling [14]. This multifactorial intervention in the trial included withdrawal of psychotropic drugs, balance and strength exercises by a physical therapist, home hazard reduction by an occupational therapist, or referral to an ophthalmologist or cardiologist. This result implies that the management of both internal and external risk factors for falls might have no results for residents with an ultra-high risk for falls. For such residents, we might be under the necessity of selecting alternative measures such as medication or hip protector to reduce fractures instead of fall prevention.

\section{External risk factors for falls and fractures (Figure 1B)}

It might be easier to control external risk factors for falls and fractures, such as those listed in Figure 1B, compared to internal risk factors (Figure 1A). Multifactorial evaluation and treatment of fall risk factors, including the assessment and improvement of external risk factors, might be effective. Keall and colleagues conducted a singleblind, cluster-randomized, controlled trial of households to test the safety benefits of home modifications including setting up of handrails, grab rails, lighting, and slip-resistant surfacing for outside areas [15]. After a median observation period of 1,148 days, the intervention groups (436 households and 950 individual occupants) showed a significant lower relative risk $(0.74,95 \%$ confidence interval: 0.58-0.94) of injuries caused by falls at home per year on multivariate analysis compared to controls ( 406 households and 898 occupants). As mentioned in the Introduction, multifactorial intervention for fall and fracture prevention might not have the desired outcome [14]. However, caregivers should assess the environmental risks of facilities and improve conditions to prevent resident falls and injuries.

\section{Impact pressure (External hip protectors) (Figure 1D)}

One way to reduce the impact force suffered by an individual might be to make the floor soft. Recently, several shock-absorbing materials have become available. However, for residents using a walker or wheelchair, it must be recognized that a soft floor interferes with the operation of these devices. Another alternative candidate for the control of impact force against the body (hip) is an external hip protector [7-9]. The hip protector consists of soft or hard shell pads embedded in garments to shunt or absorb the impact force away from the femur. Biomechanically, a hip protector can reduce the impact force under the threshold level of hip fracture [16]. However, this has not been confirmed by results of clinical trials using hip protectors to prevent hip fractures $[8,9]$, which can largely be explained by the poor adherence and acceptance of hip protectors [9]. Garments of hip protectors are tightly sewn to avoid slipping of the pad, which complicates toilet behavior in the elderly. Hip protectors are more effective for the elderly with a low BMI and a history of falls [7]. Furthermore, it is thought that hip protectors are more effective for the prevention of hip fractures among residents in nursing care settings compared to community-dwelling people, partially due to the support by caregivers or health providers $[9,17]$. It has been reported that the commitment, support, and motivation of the caregivers in the facility are essential for the acceptance of hip protectors by the residents [17]. A structured education program for caregivers increased hip protector adherence and might reduce hip fractures in nursing homes [18]. To improve acceptance and adherence of hip protectors, a better understanding of the purpose and effectiveness of hip protectors is needed. Although more randomized controlled trials (RCTs) are required to prove the clinical efficacy of hip protector, caregivers should identify candidates for hip protector user such as residents with low BMI, history of falls, or severe frailty in long-term care facilities.

\section{Low bone mineral density (Figure 1E)}

It is very difficult for caregivers to alter the conditions that cause a low BMD. However, during the last decade, several potent antiosteoporotic medicines, including bisphosphonates, teriparatide, and denosumab, have appeared [19]. These medicines dramatically increase $\mathrm{BMD}$ and significantly reduce the incidence of hip or vertebral fractures [19]. Screening is important for the effective use of these medicines, and caregivers should identify a treatment group by performing careful examinations, including the measurement of BMD. They can use several screening tools to identify candidates for BMD testing [11]. Caregivers should remember that the presence of vitamin $\mathrm{D}$ is important to achieve the effects of these strong medicines [20]. To maintain a sufficient vitamin D level, residents are recommended to take vitamin D-rich foods, such as salmon or mushrooms, and be exposed to sunlight. 
The author believes that BMD could become the target for the treatment of osteoporosis. A recent study revealed that a low BMD was the most effective predictor of fracture after the cessation of treatment with alendronate, one of the bisphosphonates [21]. On the other hand, the author has not referred to the effects of bone metabolic markers or bone quality. There is still little evidence to set these factors as targets for the treatment of osteoporosis. At least, health care managers should provide a chance for residents in long-term care facilities to receive the examination to measure BMD. And they should consult physicians for the treatment if residents show low BMD.

\section{Conclusion}

There are very many controllable or uncontrollable risk factors for falls and fractures among the elderly. Because a slight fall can lead to a bone fracture, fall prevention does not necessarily become fracture prevention. Falls might not be prevented by the great efforts made by caregivers in long-term care facilities. However, caregivers should recognize the meanings of the risk factors for falls and fractures among the elderly and the helpful measures to prevent falls and fractures, because a better understanding of these factors may ultimately lead to a reduction in the frequency and burden of fractures among older adults in long-term care facilities.

\section{Acknowledgement}

The author thanks for Miss Tomoko Nakatsuka to arrange the illustration.

\section{References}

1. Jung D, Shin S, Kim H (2014) A fall prevention guideline for older adults living in long-term care facilities. Int Nurs Rev 61: 525-533.

2. Stel VS, Smit JH, Pluijm SM, Lips P (2004) Consequences of falling in older men and women and risk factors for health service use and functional decline. Age Ageing 33: 58-65.

3. Barrett-Connor E, Weiss TW, McHorney CA, Miller PD, Siris ES (2009) Predictors of falls among postmenopausal women: results from the National Osteoporosis Risk Assessment (NORA). Osteoporos Int 20: 715-722.

4. Goodwin VA, Abbott RA, Whear R, Bethel A, Ukoumunne OC, et al. (2014) Multiple component interventions for preventing falls and fallrelated injuries among older people: systematic review and meta-analysis. BMC Geriatr 14: 15.

5. Szabo SM, Janssen PA, Khan K, Lord SR, Potter MJ (2010) Neovascular AMD: an overlooked risk factor for injurious falls. OsteoporosInt 21: 855-862.

6. Robinovitch SN, Feldman F, Yang Y, Schonnop R, Leung PM, et al. (2013) Video capture of the circumstances of falls in elderly people residing in long-term care: an observational study. Lancet 381: 47-54.
7. Koike T, Orito Y, Toyoda H, Tada M, Sugama R, et al. (2009) External hip protectors are effective for the elderly with higher-than-average risk factors for hip fractures. OsteoporosInt 20: 1613-1620.

8. Santesso N, Carrasco-Labra A, Brignardello-Petersen R (2014) Hip protectors for preventing hip fractures in older people. Cochrane Database Syst Rev 3: CD001255.

9. Sawka AM, Boulos P, Beattie K, Thabane L, Papaioannou A, et al. (2005) Do hip protectors decrease the risk of hip fracture in institutional and community-dwelling elderly? A systematic review and meta-analysis of randomized controlled trials. Osteoporos Int. 16:1461-1474.

10. Ross PD, Davis JW, Wasnich RD (1993) Bone mass and beyond: risk factors for fractures. Calcif Tissue Int 53 Suppl 1: S134-137.

11. McLeod KM, Johnson CS (2009) Identifying women with low bone mass: a systematic review of screening tools. GeriatrNurs 30: 164-173.

12. Armstrong ME, Spencer EA, Cairns BJ, Banks E, Pirie K, et al. (2011) Body mass index and physical activity in relation to the incidence of hip fracture in postmenopausal women. J Bone Miner Res 26: 1330-1338.

13. [No authors listed] (2001) Guideline for the prevention of falls in older persons. American Geriatrics Society, British Geriatrics Society, and American Academy of Orthopaedic Surgeons Panel on Falls Prevention. J Am GeriatrSoc 49: 664-672.

14. Peeters GM, Heymans MW, de Vries OJ, Bouter LM, Lips P, et al. (2011) Multifactorial evaluation and treatment of persons with a high risk of recurrent falling was not cost-effective. OsteoporosInt 22: 2187-2196.

15. Keall MD, Pierse N, Howden-Chapman P, Cunnigham M, et al. (2014) Home modifications to reduce injuries from falls in the Home Injury Prevention Intervention (HIPI) study: a cluster-randomised controlled trial. Lancet. [Epub ahead of print].

16. Laing AC, Robinovitch SN (2008) Effect of soft shell hip protectors on pressure distribution to the hip during sideways falls. OsteoporosInt 19: 1067-1075.

17. Warnke A, Meyer G, Bender R, Mühlhauser I (2004) Predictors of adherence to the use of hip protectors in nursing home residents. J Am GeriatrSoc 52: 340-345.

18. Meyer G, Warnke A, Bender R, Mühlhauser I (2003) Effect on hip fractures of increased use of hip protectors in nursing homes: cluster randomised controlled trial. BMJ 326: 76.

19. Murad MH, Drake MT, Mullan RJ, Mauck KF, Stuart LM, et al. (2012) Clinical review. Comparative effectiveness of drug treatments to prevent fragility fractures: a systematic review and network meta-analysis. J Clin Endocrinol Metab 97: 1871-1880.

20. Carmel AS, Shieh A, Bang H, Bockman RS. (2012) The 25(OH)D level needed to maintain a favorable bisphosphonate response is $=33 \mathrm{ng} / \mathrm{ml}$. Osteoporos Int. 23: 2479-2487.

21. Bauer DC, Schwartz A, Palermo L, Cauley J, Hochberg M, et al. (2014) Fracture prediction after discontinuation of 4 to 5 years of alendronate therapy: the FLEX study. JAMA Intern Med 174: 1126-1134. 